\title{
ENCENAC̣ÕES DA ESCRITA NOS TEXTOS DE ADÍLIA LOPES
}

\author{
MISES-EN-SCÈNE OF WRITING IN THE TEXTS BY ADÍLIA LOPES
}

\author{
Olga Kempinska* \\ Universidade Federal Fluminense, Niterói, RJ, Brasil
}

\begin{abstract}
Resumo: Nos poemas e nas narrativas-fragmentos de Adília Lopes trata-se de um intenso convivio com a tessitura da morte e de um significativo deslocamento de sua representação do domínio consagrado pela tradição - 0 das flores, dos ossos e das conchas - para 0 âmbito dos materiais da escrita. Ee é justamente nesse deslocamento, que distancia a encenação da relação entre escrita e desejo do contexto da natureza, que consiste a singularidade dos textos da poeta portuguesa nos dias de hoje. Com efeito, a perturbadora confusão entre as posturas estética, prática e mágico-religiosa, delimitadas no âmbito do Círculo Linguístico de Praga por Jan Mukarovski, vê-se encenada em muitos dos textos de Adélia Lopes que relatam fatos aparentemente corriqueiros, apontando para os perigos da pseudo-racionalidade totalitária. De fato, a renúncia ao caráter arbitrário do signo, típica da função mágica, é característica também de certos estados de um delírio psicótico que procura gratificações brutas para impulsos agressivos. Dessa forma, a denúncia do considerável enfraquecimento da eficácia da função estética em prol da função mágica, característica da superstição, torna-se o foco de sua exigente poética, na qual a lógica da metonímia e a referencialidade negativa se revelam instrumentos necessários da resistência subjetiva.
\end{abstract}

Palavras-chave: Escrita; Adulia Lopes; Jan Mukarovsky; Função estética; Ética.

Abstract: Poems and narrative-fragments by Adilia Lopes relate to an intense interaction with the composition of death and a significant displacement of its representation from the domain acclaimed by the tradition - that of flowers, bones and shells - as for the realm of writing materials. Moreover, it is in this very displacement, that disassociates the mise-en-scène of the relation between writing and desire away from the context of nature, which consists of the singularity of the Portuguese poet. In fact, the disturbing confusion of the esthetic postures, the practical and the magically-religious ones, delineated in the ambit of the Prague Linguistic Circle by Jan Mukarouski, is represented in numerous texts by Adilia Lopes which narrate apparently ordinary facts, pointing to the dangers of the totalitarian pseudo-rationality. In fact, the renunciation of the arbitrary character of sign, typical of the magical function, is also characteristic of some states of the psychotic delirium, which seeks brutal gratifications of aggressive impulses. Thus, the denunciation of the enfeeblement of the esthetic function's efficacy in favour of the magical function, characteristic of the superstition, becomes the focus of her demanding poetics, in which the logic of metonymy and the negative referenciality prove to be the indispensable instruments of the subjective resistance.

Keywords: Writing; Adilia Lopes; Jan Mukarovsky; Aesthetic Function; Ethics.

* Universidade Federal Fluminense - UFF, Niterói, RJ, Brasil; olgagkem@gmail.com

http://dx.doi.org/10.11606/issn.2236-4242.v32i2p127-144 
Linha D'Água (Online), São Paulo, v. 32, n. 2, p. 127-144, maio-ago. 2019

\section{Introdução}

$\mathrm{E}$, no entanto, se a dita igualdade deixasse fremir um pequeno sopro de tudo "isso" na chamada vida política..., Mas estou sonhando, naturalmente, forçosamente, com todas essas benditas mulheres.

Julia Kristeva

De forma muito semelhante à indústria cultural, a astrologia tende a eliminar a distinção entre fato e ficção.

Theodor W. Adorno

A máquina de escrever só tornará alheia à caneta a mão do literato quando a exatidão das formações tipográficas entrar imediatamente na concepção de seus livros. Provavelmente serão necessários então novos sistemas, com configuração de escrita mais variável. Eles colocarão a inervação dos dedos que comandam no lugar da mão cursiva.

Walter Benjamin

Uma revista americana da qual a pequena Adília, que ainda desconhece o inglês, recorta figurinhas; uma redação joyciana escrita à tinta sépia e jogada no lixo; um livro cruelmente despedaçado e sem capa; um verso de Rimbaud esquecido e reduzido pela memória a um rasto do avião no céu: nas numerosas encenações das reminiscências do sujeito lírico de Adília Lopes, o texto escrito obstina-se em retornar como um texto falho. Ademais, a avó rasga a carta anterior quando recebe uma nova, para "ter certeza" (LOPES, 2016, p. 193) de que a remetente, uma prima brasileira, continua viva. Uma das mais instigantes lembranças linguísticas tem, aliás, como seu centro de gravidade a diferença fonológica e gráfica existente no seio do próprio português, a saber, a perturbadora heterogeneidade da língua aparentemente própria, relacionando-se explicita e ironicamente com o vocabulário psicanalítico. Nessa recordação, o sujeito lírico relata que no livro brasileiro "Acto falhado era ato falho", acrescentando ainda, fascinado: "Ainda hoje gosto de dizer ato falbo" (LOPES, 2015, p. 17). Em outra lembrança linguística surge inclusive

KEMPINSKA, O. Encenações da escrita nos textos de Adilia Lopes 
um lapsus linguae de um colega da escola que "disse sexo treze em vez de o século XIII' (LOPES, 2016, p. 115), apontando para a continuidade entre a linguagem e a economia do desejo.

Ora, justamente onde e quando o acesso à boa legibilidade do texto se vê de alguma forma comprometido, o fascínio fetichista pelos materiais da escrita tornase mais insistente. Nesse sentido, ao inscrever o tema do fetichismo no contexto da ameaça da castração freudiana, Agamben atrela-a à dolorosa cisão do eu, que acaba por experimentar "a presença do nada” (AGAMBEN, 2007, p. 60). Destarte, a estrutura fetichista passa a assemelhar-se ao funcionamento da metonímia, tendo como seu âmbito de predileção a lógica da contiguidade. Não raramente ela se vê também submetida à ordem da referencialidade negativa, segundo a qual o objeto é ao mesmo tempo evocado e negado. A estética do fragmento que articula a escrita dos livros da poeta portuguesa, assim como o trabalho com as citações -ruinas, por vezes transformadas em coleções, igualmente parecem confirmar a economia do fetichismo subjacente à encenação dos gestos da escrita. Em meio a diversos naufrágios linguísticos, nos quais se rompem os limites entre a linguagem, o corpo, os materiais da escrita e os objetos do mundo, aflora então um universo de monstruosas metamorfoses, "infantil, irônico e perverso, o espelho ao mesmo tempo doméstico e misterioso de Alice, menina 'exemplar' de Lewis Carroll” (PEDROSA, 2011, p. 204).

\section{Desenvolvimento}

Em uma entrevista de 2017, a poeta comenta a importância da "resistência" dos materiais para a sua própria escrita:

JF [Jogos Florais] Escreve à mão?

AL [Adília Lopes] Eu não tenho computador. Escrevo à mão e à máquina, numa máquina que não é eléctrica. É uma Olivetti.

JF De que cor?

AL Eu escolhi a cor. É azul turquesa.

JF E não se imagina a escrever a computador?

$\mathrm{AL} \mathrm{Eu} \mathrm{já} \mathrm{escrevi} \mathrm{a} \mathrm{computador,} \mathrm{mas} \mathrm{não} \mathrm{gostei...} \mathrm{E}$ eu não tenho ninguém que me ajude com o computador, era eu que me desemburrava sozinha. Se havia

KEMPINSKA, O. Encenações da escrita nos textos de Adúlia Lopes 


\section{Linha D'Água (Online), São Paulo, v. 32, n. 2, p. 127-144, maio-ago. 2019}

algum problema com computador, tinha de ir de táxi à loja, não tinha ninguém que me ajudasse. Eu escrevia a computador as crónicas, numa disquete. Mas o que eu notei é que escrevia pior, os textos ressentem-se, saem piores...

JF Mas porquê? Por ser mais rápido?

AL Porque no computador parece tudo muito fácil, sabe bem, a pessoa gosta de estar ali a dedilhar... Parece fácil, a pessoa está ali a escrever e até dá ideia de que está a escrever um romance. Noutros casos sairá muito bem, no meu não sai. Eu acho que preciso do tempo e de alguma resistência do material. Sinto isso. (Jogos Florais, 2017, s/p).

De acordo com as palavras de Adília Lopes, a aparente facilidade da escrita no computador, que tem como seu atributo a velocidade facilmente transformada em quantidade, releva-se inimiga da qualidade da linguagem poética. Com isso, a poeta junta-se ao questionamento da relação entre cultura, sociedade e barbárie, que ao longo do século passado se tornou um dos temas principais dos diversos pensadores, tais como, por exemplo, Walter Benjamin, preocupados com a veemência do apelo dos fascismos. Diferentemente da experiência da transcrição, a distância garantida por certas leituras pode ser expressada por meio de uma metáfora militar:

A força da estrada do campo é uma se alguém anda por ela, outra se a sobrevoa de aeroplano. Assim é também a força de um texto, uma se alguém o lê, outra se o transcreve. Quem voa vê apenas como a estrada se insinua através da paisagem, e, para ele, ela se desenrola segundo as mesmas leis que o terreno em torno. Somente quem anda pela estrada experimenta algo de seu domínio e de como, daquela mesma região que, para o que voa, é apenas a planície desenrolada, ela faz sair, a seu comando, a cada uma de suas voltas, distâncias, belvederes, clareiras, perspectivas, assim como o chamado do comandante faz sair soldados de uma fila. Assim comanda unicamente o texto copiado a alma daquele que está ocupado com ele, enquanto um mero leitor nunca fica conhecendo as novas perspectivas de seu interior, tais como as abre o texto, essa estrada através da floresta virgem interior que sempre volta a adensar-se: porque o leitor obedece ao movimento de seu eu no livre reino aéreo do devaneio, enquanto o copiador o faz ser comandado. A arte chinesa de copiar livros foi, portanto, a incomparável garantia de cultura literária, e a cópia, uma chave para os enigmas da China. (BENJAMIN, 1987, p. 16)

KEMPINSKA, O. Encenações da escrita nos textos de Adília Lopes 
"Para quê sacrificar mais uma página em branco? / se ainda se escrevesse em peles de bezerros recém-nascidos" (LOPES, 2002, p. 35), pergunta-se o sujeito lírico de uma das narrativas-fragmentos. Impiedosamente inscritas no contexto de gestos violentos, os de rememoração de "histórias de (mau) exemplo" (SILVESTRE, p. 41), as encenações adilianas da escrita acabam por funcionar também como um instigante questionamento do erotismo em sua relação com o gênero. Marguerite Duras que, ao expor em seus textos a dilacerante vivência da dor física e psíquica, sobretudo da sexualidade e do alcoolismo, reafirmou a inevitabilidade dos maus exemplos no domínio da escrita feminina, formulou essa experiência da seguinte maneira: "Escrever não é contar histórias. É o oposto de contar histórias. É tudo ao mesmo tempo. É contar uma história e a ausência dessa história. É contar uma história que passa por sua ausência" (DURAS, 1989, p. 28). Além do forte apego pela forma do fragmento, que frequentemente acaba por debruçar-se sobre a escrita em sua dimensão existencial e fenomenológica, Duras compartilha com Adília Lopes a necessidade de um pseudónimo e a experiência da intensa solidão que "está sempre acompanhada de loucura" (DURAS, 1993, p. 44), revelando-se, contudo, indispensável ao fazer poético, e com isso, paradoxalmente, protetora da intimidade do sujeito.

Fizemos amor de novo. Já não conseguíamos conversar. Bebíamos. A sangue-frio, ele batia. No rosto. E em certos lugares do corpo. Já não conseguíamos chegar perto um do outro sem ter medo, sem tremer. Ele me levou até o alto do parque, até a entrada do castelo. Lá estava o pessoal da funerária, os caseiros do castelo, a governanta da minha mãe e meu irmão mais velho. Minha mãe ainda não foi posta no caixão. Minha mãe. Beijei a fronte gelada. (DURAS, 1989, p. 16-17)

De fato, subvertendo aquele "viés predominantemente falocêntrico da poesia erótica” (PAES, 1990, p. 16), que encontrou sua voz principal na obra de George Bataille, afirmando a inevitabilidade da relação entre "o desejo e o medo, o prazer intenso e a angústia” (2011, p. 42), Adília Lopes procura operar também uma desestabilização criativa da relação entre o erotismo e a violência. Assim, ironicamente vinculada à articulação tradicional retrógrada da sexualidade feminina - que faz com que se distinga, ou até mesmo com que se opunha o prazer ao gozo, 
consolidando a ambivalência de atração e de repulsa -, assim como a sua formulação histórica em discursos que fazem do corpo feminino o "lugar eleito de sofrimento e de mortificação" (BIDAUD, 1998, p. 36) -, a obsessão pela materialidade da escrita repetidamente desagua em metáforas alimentares. A vertigem do contato incestuoso que subjaz a essa aproximação possui como seu impulso o desejo do desejo, que, diferentemente das experiências de excesso relatadas nos textos de Duras, mantem-se na sua modalidade do desejo.

“O meu bairro é um oásis" (LOPES, 2016, p. 125) revela ironicamente o sujeito lírico adiliano, assemelhando-se a muitas outras vozes femininas, tais como, por exemplo, a brasileira Hilda Hilst ou a uruguaia Marosa di Giorgio, que empreenderam a dolorosa tarefa da denúncia da sufocante morbidez dos abusos de poder nos universos fechados. De fato, tendo acesso à escrita criativa - uma genuína escapatória que torna possível negociar os tratos com o Outro, segundo o qual uma menina "imagina sua própria completude corporal" (BOONS, 1992, p. 37) -, o sujeito adiliano furta-se às injunções das representações da inércia sofrida do corpo erótico feminino.

Articuladas em discursos toscos, as representações da experiência da feminilidade ironicamente aludem àquele mundo (auto)alienado das trocas simbólicas, cercado pelos entraves da família e da vizinhança, fechado sobre si mesmo, sendo seu próprio vigia e tendo um impressionante potencial de auto-alimentação enquanto um universo pequeno-burguês de "manipulação financeira da chantagem sentimental” (KRISTEVA, 2001, p. 20), no qual a endogamia, o ócio, a mesquinharia, a vulgaridade, a burrice e a crueldade estimulam o surgimento da perversidade em suas modalidades mais veementes e mais doentias, tendo como sua pior ameaça a morte psíquica, ou seja, o aniquilamento da boa solidão e a devastação irremediável da intimidade e da interioridade do sujeito.

No princípio dos anos 70, nos livros para raparigas que eu lia, aparecia a palavra flirt em itálico. Eu não sabia o que queria dizer flirt. Sabia que flirt tinha a ver com namorar. Mas não percebia muito bem. Num livro, um rapaz e uma rapariga cruzavam os olhares reflectidos sobre um aquário. Isso era flirt. Pensei que flirt fosse um fenómeno de óptica. O itálico na minha cabeça ficou para sempre associado ao sexo. (LOPES, 2015, p. 60)

KEMPINSKA, O. Encenações da escrita nos textos de Adília Lopes 
Linha D'Água (Online), São Paulo, v. 32, n. 2, p. 127-144, maio-ago. 2019

Relacionar diretamente o erotismo à heteroglossia e à grafia, ou seja, à materialidade da escrita, é o gesto que na obra de Adília Lopes adquire uma radicalidade particular. "Para mim os nomes são coisas" (LOPES, 2015, p. 98), "Adoro nomes e códigos" (LOPES, 2016, p. 49), confessa impudicamente o sujeito lírico. Deleitosamente vulnerável, o próprio pseudônimo "Adília Lopes", que constitui uma genuína "microfiç̧ão" (MARTELO, 2010, p. 210), suscita o fascínio do sujeito falante ao aparecer declinado, ou então, escrito em caracteres cirílicos em um jornal de Sarajevo. Sendo presenças de ausências, investidos de um potencial infinito de desdobramento metonímico, os gestos da escrita adilianos acabam por confundir-se abertamente com a experiência da dança em uma das narrativasfragmentos do volume Manhã: "Desde que comecei a dansar escrevo dansar com s como a Sophia" (LOPES, 2015, p. 77). A atividade de "girar sobre si mesmo" (FECHNER, 1998, p. 75) transforma-se então no prazeroso movimento centrípeto de "ordenar ou organizar nossos movimentos de dissipação" (VALÉRY, 2003, p. 29). Em sua consideração sobre a relação entre desenho, escrita e pensamento Alain conclui: "A cada um de dominar seus diabos" (ALAIN, 1970, p. 586).

Tal como a pintora Georgia O'Keeffe, muito admirada por Kristeva - pensadora migrante que chega a aparecer enquanto tema de uma das narrativas-fragmentos do recente volume Bandolim (2016), justamente enquanto uma quase presença -, Adília Lopes é uma "exploradora modesta do inominável" (KRISTEVA, 2001, p. 52). De fato, aquilo "que ocorre com o instinto da morte, ocorre com a libido” (SEGAL, 1975, p. 37), ou, nas palavras de Kristeva, na arte a morte passa a ser celebrada, por exemplo por Georgia O'Keeffe, "como se ela fosse uma flor" (KRISTEVA, 2013, p. 20). Cioran formulou essa tendência ambivalente intrínseca à arte em um de seus aforismos: "Toda palavra me faz sofrer. No entanto, como seria doce ouvir flores tagarelando sobre a morte!" (CIORAN, 2001, p. 15). Um dos poemas mais evocativos que encenam a morte como uma flor, contemporâneo de Cioran, parece ser o de Celan:

Der Tod ist eine Blume, die blübt ein einzig Mal.

Doch so er blüht, blübt nichts als er.

KEMPINSKA, O. Encenações da escrita nos textos de Adília Lopes

Todo conteúdo da Linha D'Água está sob Licença Creative Commons Attribution-NonCommercial 4.0 International License 
Linha D'Água (Online), São Paulo, v. 32, n. 2, p. 127-144, maio-ago. 2019

Er blübt, sobald er will, er blübt nicht in der Zeit.

Er kommt, ein großer Falter, der schwanke Stengel schmückt.

Du laß mich sein ein Stengel, so stark, daß er ihn freut.

A morte é uma flor que só abre uma vez.

Mas quando abre, nada se abre com ela.

Abre sempre que quer, e fora de estação.

E vem, grande mariposa, adornando caules ondulantes.

Deixa-me ser o caule forte da sua alegria.

(CELAN, 1998, p. 15)

A própria O'Keeffe expressou sua atração pela representação dos ossos da seguinte maneira: "Os ossos pareciam penetrar de forma brusca algo que está intensamente vivo no deserto, ainda que se trate de algo vasto, vazio e intocável - e que em meio a sua beleza desconhece a candura" (LISLE, 1981, p. 243). Nos poemas e nas narrativas-fragmentos de Adília Lopes trata-se, com efeito, de um vigoroso convívio com a tessitura da morte, senão de uma desesperada e nunca garantida tentativa de se "domesticar a morte" (KRISTEVA, 2013, p. 177) por meio do deslocamento de sua representação do domínio consagrado pela tradição - o das flores, dos alimentos, dos ossos e das conchas - para o contexto dos diversos materiais da escrita. E é justamente nesse deslocamento que audaciosamente reinventa a encenação desgastada da relação entre escrita e desejo, afastando-a do âmbito orgânico, que, em meu ver, consiste a singularidade da escrita da poeta portuguesa.

De fato, o poeta é aquele que faz. "Faz o quê? Faz linguagem", explica Pignatari, para logo confundir a impressão da simplicidade aforística da sua afirmação: "E aqui está a fonte principal do mistério" (PIGNATARI, 1978, p. 4). Pois o "fazer" tem como sua condição de possibilidade alguma falta, senão alguma urgência, e, com efeito, a poesia investiga sem piedade as experiências nas quais a linguagem corre o risco de fazer falta. Assim, ela não é transformação, enriquecimento e nem mesmo desvio. Se o poeta "trabalha" o signo verbal é, antes, em um gesto de desesperada resistência à queda dos signos em descuido, ou seja, em um estado de naturalizada "descriação" (PIGNATARI, 1978, p. 5).

KEMPINSKA, O. Encenações da escrita nos textos de Adilia Lopes 
Linha D'Água (Online), São Paulo, v. 32, n. 2, p. 127-144, maio-ago. 2019

Atrelada às ambivalências do segredo, a escrita encenada na obra adiliana inevitavelmente se vincula aos jogos do saber, hesitando entre desvelamento e dissimulação, mas também entre visibilidade e legibilidade, e tendo como seus correspondentes tangíveis diversos objetos que tornam vulneráveis os limites entre espaços, a saber, “objetos materiais como gavetas, portas, escadas etc.”(VINCENT, 2009, p. 162). Assim, por exemplo, aparentado com uma cômoda guarda-joias, mas também com um diário que pode ser fechado à chave, o calendário do Advento, que tinha uma janelinha para cada dia e "que se abria nesse dia" (LOPES, 2015, p. 122), faz parte do elenco dos materiais marcados pelo sufocante trabalho do segredo e do segredo. Inscritos no contexto das tensões da referencialidade negativa, tal o livro que "não é um livro" (LOPES, 2015, p. 116), mas uma caixa de tintas, e fortemente investidos pelo desejo, os materiais veem-se, de fato, sujeitos ao excesso de "parentescos" visuais que descambam em fantásticas transformações, cujo denominador comum é a reversibilidade entre o dentro e o fora.

Sonâmbulos como as linhas de Henri Michaux (1993), que hesitam entre desenho e escrita, e que acabam por traçar "uma espécie de pictogramas" (MICHAUX, 1993, p. 13), os materiais encenados nos textos adilianos vacilam entre o status de objeto superfluamente decorativo e o de um instrumento eficaz. Enquanto gesto e como prática, a própria experiência da escrita é relatada por Sartre no capítulo final do trabalho Esboço de uma teoria das emoções, de 1939, que se debruça sobre as emoções compreendidas, no sentido fenomenológico, como formas de apreensão do mundo:

No momento em que traço uma delas [palavras], não presto atenção isoladamente em
cada uma das pernas de letras que minha mão forma: estou num estado especial de
espera, a espera criadora, espero que a palavra - que sei de antemão - sirva-se da mão
que escreve e das pernas de letras que ela traça para se realizar. (SARTRE, 2008, p. 59)

Não muito distante da reflexão de Valéry acerca da experiência fundamentalmente construtiva e estruturante da dança, o filósofo francês ressalta a compenetração tranquila necessária à criatividade que acompanha o gesto da escrita: 
Linha D'Água (Online), São Paulo, v. 32, n. 2, p. 127-144, maio-ago. 2019

(...) a exigência das palavras que traço é diretamente presente, sentida e pesada. Elas puxam e conduzem minha mão. Mas não à maneira de pequenos demônios espertos e ativos que a empurrariam e puxariam: elas têm uma exigência passiva. Quanto à minha mão, tenho consciência dela no sentido de que a vivo diretamente como o instrumento pelo qual as palavras se realizam. (SARTRE, 2008, p. 61)

Tal como detalhada por Sartre, a experiência da escrita permite reafirmar a inscrição do sujeito no âmbito do simbólico, inclusive naquilo que tange à experiência asseguradora da sua completude corporal. Nesse mesmo sentido, ao refletir acerca dos gestos da escrita do ponto de vista antropológico e ao insistir em sua convergência com os do desenho, Tim Ingold confirma a abrangência da analogia existente entre a imagem da elaboração de um texto e os trabalhos manuais que implicam a manipulação de tecidos, necessitando, com isso, do exercício da violência contida, ou seja, da delicadeza:

Compreendida antes como um tecer de fios do que como um martelar de teclas, melódica antes de percussiva, a escrita pode ser comparada à costura ou ao bordado, e a ideia do texto enquanto algo tecido demonstra ser não apenas uma mera metáfora sem consistência, e sim a descrição conforme daquilo que de fato acontece. (INGOLD, 2011, p. 178 , tradução minha)

Ora, na escrita adiliana as palavras parecem possuir justamente um quê dos "pequenos demônios" dotados de uma inquietante atividade, rebelde ao corpo do qual se distanciam, sendo metonimicamente transferidas para os materiais da escrita e, o mais grave, para outros objetos que se lhes assemelham visual ou funcionalmente. A poeta portuguesa capta em sua obra os perigos - éticos e políticos - da doentia perversidade que corrompe a relação entre o sujeito, o mundo e a sua representação.

Em sua conferência de 1942 intitulada "O significado da estética" o teórico tcheco Jan Mukarovsky (1975) delimitou algumas posturas humanas, introduzindo uma curiosa distinção entre a "função mágico-religiosa" e a "função estética". Essa distinção, esquecida, como veremos, pelo estruturalismo dos anos 50 e 60, mas nem por isso pouco pertinente, e mais ainda nos dias de hoje, parece operativa

KEMPINSKA, O. Encenaçōes da escrita nos textos de Ad́lila Lopes

Todo conteúdo da Linha D'Água está sob Licença Creative Commons Attribution-NonCommercial 4.0 International License 
para a tentativa de se evitar a redução do alcance do fazer poético de Adília Lopes. Mukarovsky descreveu, de fato, quatro funções, anunciando, com isso, a conhecida nomenclatura de Roman Jakobson (1995): a prática, a teórica, a mágico-religiosa e a estética. $\mathrm{Na}$ função prática procura-se influenciar diretamente a realidade e, com isso, escolhe-se os instrumentos considerados do ponto de vista de sua eficácia. $\mathrm{Na}$ teórica, o objetivo sendo o conhecimento da realidade, limita-se a diversidade desta a certos aspectos. Na função estética, descrita mais tarde no sistema jakobsoniano como função poética, o signo não apenas adquire um valor em si mesmo, como também "alude a todas as realidades que um ser humano experimentou ou possa experimentar, ao universo inteiro de coisas e processos” (MUKAROVSKY, 1975, p. 148).

No caso da função mágico-religiosa - ausente da proposta de Jakobson que se debruça apenas sobre a "função conativa", predominante, por exemplo, na propaganda -, "o peso não reside no símbolo, e sim no poder invisível por este encarnado”(MUKAROVSKY, 1975, p. 149). A especificidade da função mágico-religiosa, que compartilha com a função estética a capacidade de transformar a realidade em signos, consiste, com efeito, no abandono do caráter arbitrário do signo. Uma tal abdicação é, contudo, característica também de certos estados de um delírio psicótico que procura gratificações brutas para impulsos agressivos: "Na postura mágico-religiosa os fatos reais não se convertem em signos, mas são signos de maneira substancial; justamente por este motivo são capazes de atuar como aquilo que representam (um amuleto, etc.). Trata-se de signos-símbolos" (MUKAROVSKY, 1975, p. 147).

A veemente irrupção da função mágico-religiosa faz com que se possa interpretar as encenações adilianas da escrita como tentativas de denúncia do considerável enfraquecimento da função estética no seu papel de um componente vital do comportamento humano em uma sociedade cada vez mais entregue à coisificação e à barbárie. Outrossim, ao analisar detalhadamente os elementos da regressão intelectual dos leitores da coluna de astrologia de uma revista americana dos inícios dos anos 50, Adorno insistiu na gravidade da deterioração subjetiva que condiciona seus efeitos: 
Linha D'Água (Online), São Paulo, v. 32, n. 2, p. 127-144, maio-ago. 2019

(...) nas comunidades secundárias, as pessoas não mais "vivem juntas", e tampouco conhecem a si mesmas diretamente, mas relacionam-se umas com as outras mediante processos sociais intermediários objetivados (por exemplo, a troca de mercadorias), também as pessoas que respondem ao estímulo que investigamos aqui parecem de alguma forma "alienadas" da experiência na qual poderiam afirmar que suas decisões estão baseadas. (ADORNO, 2008, p. 33)

A alienação da experiência tem por consequência um considerável enfraquecimento da subjetividade, sua incapacidade de se voltar para qualquer postura estética enriquecedora da experiência, e seu abandono aos abusos de poder autoritários:

Assim, podemos assumir que apenas exigências instintuais muito fortes podem fazer que
as pessoas ainda aceitem ou venham a aceitar a astrologia. Sob as atuais circunstâncias,
o sistema astrológico pode funcionar apenas como "superstição secundária",
majoritariamente excluída do controle crítico do indivíduo, e oferecida de maneira
autoritária. (ADORNO, 2008, p. 35)

A perturbadora confusão entre as posturas estética, prática e mágico-religiosa, encenada em muitos dos textos de Adília Lopes que relatam fatos aparentemente corriqueiros, aponta para os perigos da pseudo-racionalidade totalitária, cuja descrição e crítica foram elaboradas por Adorno no devastador contanto com o fascismo alemão e com o capitalismo americano:

É necessário frisar esse caráter de "superstição secundária”, uma vez que ele oferece a chave para um dos elementos mais estranhos do material que estamos investigando. Trata-se exatamente da pseudo-racionalidade, o mesmo traço que desempenha um papel tão evidente nos movimentos sociais totalitários, a adaptação calculista - e, no entanto, espúria - às necessidades realistas. (ADORNO, 2008, p. 35-36)

Diferentemente de um autor de horóscopo, Adília Lopes - que lança mão da técnica do fragmento aparentemente solidária de uma leitura mais acessível pelo fato de dispensar o esforço da continuidade - não oferece ao seu leitor o conforto baseado na lisonja ou alguma promessa de gratificação. As narrativas-fragmentos não deixam, de fato, de abrir perante o leitor a promessa da posse, tanto perceptiva quanto imaginativa, cujas ambivalências foram muito bem descritas por Benjamin:

KEMPINSKA, O. Encenações da escrita nos textos de Adilia Lopes 
Linha D'Água (Online), São Paulo, v. 32, n. 2, p. 127-144, maio-ago. 2019

\begin{abstract}
Nuvens de gafanhotos de escritura, que hoje já obscurecem o céu do pretenso espírito para os habitantes das grandes cidades, se tornarão mais densas a cada ano seguinte. Outras exigências da vida dos negócios levam mais além. A cartoteca traz consigo a conquista da escrita tridimensional, portanto um surpreendente contraponto à tridimensionalidade da escrita em suas origens como runa ou escritura de nós. (BENJAMIN, 1987, p. 28)
\end{abstract}

A acessibilidade proporcionada pela estrutura fragmentária dos recentes volumes Manhã e Bandolim encontra um significativo contrapeso na encenação da violência específica da linguagem poética, encontrando no humor ambivalente um instrumento particularmente eficaz. Assim, transformadas em pequenos demônios, as palavras e os objetos supostamente "representados", longe de proporcionar levam, antes, à crescente sensação de desamparo. Além disso, a imagem implícita do leitor de colunas de astrologia é "predominantemente masculina" (ADORNO, 2008, p. 79). Um autor de horóscopos "parece saber que as mulheres normalmente sentem-se lisonjeadas se forem tratadas como homens" (ibidem), nota o filósofo alemão. Assim, a "imagem padrão é a de uma pessoa jovem, por volta dos trinta anos, vigorosamente engajada em seus projetos profissionais, entusiasta de prazeres que devem ser de alguma forma controlados, e inclinada ao romance" (idem, p. 80). Outrossim, "não se faz nenhuma referência ao nível educacional do leitor" e "não faz nenhuma diferença se o leitor fez faculdade, parou no ensino médio ou apenas foi alfabetizado" (idem, p. 81). Na poética adiliana, uma vez que os textos da poeta portuguesa confrontam seu fruidor com os maus exemplos da história da família e da educação, inclusive superior, sendo ainda intercalados com diversas confidências do mal-estar psicossomático, tais como, por exemplo, bruscas mudanças de peso, a imagem implícita do leitor revela-se tremendamente irônica.

Ao enchergar em Mallarmé e, sobretudo, na conflagração gráfica de Um lance de dados nunca abolirá o acaso um dos primeiros sinais de inquietação causada pela crescente devastação da palavra, Benjamin assinalou as ambivalências éticas e estéticas das transformações da escrita em seus usos e aspectos materiais. Adília Lopes aproveita-se da figura do poeta francês em um texto que se desenvolve em torno ao jogo irónico com o verbo "gostar" e com o substantivo "livro": 
Linha D'Água (Online), São Paulo, v. 32, n. 2, p. 127-144, maio-ago. 2019

\author{
Não gosto tanto \\ de livros \\ como Mallarmé \\ parece que gostava \\ eu não sou um livro \\ e quando me dizem \\ gosto muito de seus livros \\ gostava de poder dizer \\ como o poeta Cesariny \\ olha \\ eu gostava \\ é que tu gostasses de mim \\ os livros não são feitos \\ de carne e osso \\ e quando tenho \\ vontade de chorar \\ abrir um livro \\ não me chega \\ preciso de um abraço \\ mas graças a Deus \\ o mundo não é um livro \\ e o acaso não existe \\ no entanto gosto muito \\ de livros \\ e acredito na Ressureição \\ dos livros \\ e acredito que no Céu \\ haja bibliotecas \\ e se possa ler e escrever.
}

(LOPES, 2002, p. 189-190)

O poema inscreve-se em palimpsesto em uma das mais discutidas divagações poéticas de Mallarmé, que traz consigo a utopia do livro universal: "Uma frase que emana de mim - se, diferentemente, citada em meu elogio ou em censura - eu a reivindico com aquelas que por aqui passarão - sumária quer que tudo, no mundo, exista para acabar em um livro" (MALLARMÉ, 1947, p. 379). 
Lançando mão de um ritmo acelerado pela brevidade dos versos, de um excesso de repetições que chegam a produzir um efeito de permutação, da referencialidade negativa, da metáfora alimentar e da intertextualidade, o poema confunde os regimes erótico-sentimental e sagrado, sugerindo que seu contrapeso talvez seja a experiência estética proporcionada pela leitura e pela escrita. Ao analisar a linguagem poética enquanto uma estrutura verdadeiro-falso, positivo-negativo e real-fictício, Kristeva vê, de fato, na negação a base da atividade simbólica, senão "o ponto nevrálgico em que se articula o funcionamento do simbólico” (KRISTEVA, 1974, p. 167):

Será devido a esse "entrelaçamento desnorteante" do positivo e do negativo, do real e do não-real (entrelaçamento que a lógica do discurso foi incapaz de pensar a não ser como anomalia), que a linguagem poética (esta antidiscurso) é considerada um fora-da-lei, dentro de um sistema regido pelos postulados platônicos? (KRISTEVA, 1974, p. 170)

Com efeito, se há na obra de Adília Lopes traços de alguma “imaginação pornográfica” (SONTAG, 1987, p. 74) estimuladora do teor transgressor das obras de, por exemplo, Bataille, estes se veem rapidamente neutralizados pelo prazer intelectual e afetivo proporcionado pelo universo dos textos. Conhecido intimamente dos escritores de diários e de cartas, mas também por aqueles que aprendem os textos de cor, o excesso dessa experiência é descrito em termos de uma "sedução" por Frances Wilson (2000), que, ao debruçar-se sobre os textos de Elizabeth Barrett e Robert Browning, de Anaïs Nin e Henry Miller, de Laura Riding e Robert Graves, e de Ossip e Nadejda Mandelstam, insiste na relevância subjetiva do prazer experimentado no contato com os textos:

No caso de seduções literárias as palavras tornam-se carne. (...) Nas seduções literárias em sua forma pura a paixão que compartilham os amantes não tem pelo objeto suas respectivas pessoas e sim a própria linguagem. Desta maneira, eles acabam preferindo a vida na página àquela além do texto impresso. (WILSON, 2000, p. 14, tradução minha)

\section{Conclusão}

Considerada não apenas enquanto um dispositivo para a atividade da imaginação, mas também como uma prática carregada de desejo e, com isso, investida 
Linha D'Água (Online), São Paulo, v. 32, n. 2, p. 127-144, maio-ago. 2019

pela inscrição do sujeito no regime ético e político, a escrita encenada nas narrativas-fragmentos de Adília Lopes torna-se uma ocasião para uma reflexão acerca da urgência da resistência individual nos tempos da crescente massificação. De fato, é no contato com a encenação da escrita considerada em seus aspectos materiais que o leitor dos textos adilianos se vê constantemente colocado em situação de luta por seus limites, principalmente por causa dos efeitos do humor ambivalente e da pulsante intensidade de uma estrutura fraturada em fragmentos. Pois a riqueza das perspectivas daquilo que Benjamin chamou de "interior" de um texto e que pode ser espelhado apenas na interioridade do sujeito, remetendo a situações de recolhimento e de compenetração, encontra seu contraponto na distância e na velocidade proporcionadas pelo uso da máquina e, mais ainda, do computador e do celular.

\section{Referências}

ADORNO, T. W. As estrelas descem à Terra. A coluna de astrologia do Los Angeles Times. Um estudo sobre a superstição secundária. Trad. P. Rocha de Oliveira. São Paulo: Editora UNESP, 2008.

AGAMBEN, G. Estâncias. A palavra e o fantasma na cultura ocidental. Trad. S. J. Assmann. Belo Horizonte: Editora UFMG, 2007.

ALAIN. Propos II. Pléiade. Paris: Gallimard, 1970.

BATAILLE, G. L'érotisme. Paris: Les Éditions de Minuit, 2011.

BENJAMIN, W. Rua de Mão Única. Trad. R. Rodrigues Torres Filho e J. C. Martins Barbosa. São Paulo: Brasiliense, 1987.

BIDAUD, É. Anorexia mental, ascese, mística. Uma abordagem psicanalítica. Trad. D. Duque Estrada. Rio de Janeiro: Companhia de Freud, 1998.

BOONS, M-C. Mulheres Homens. Ensaios Psicanalíticos sobre a Diferença Sexual. Rio de Janeiro: Dumará, 1992.

CELAN, P. A morte é uma flor. Poemas do Espólio. Trad. J. Barrento. Lisboa: Cotovia, 1998.

CIORAN, É. Silogismos da amargura. Trad.J. T. Brum. Rio de Janeiro: Rocco, 2011.

DURAS, M. A vida material. Trad. H. Jahan. Rio de Janeiro: Globo, 1989. 
Linha D'Água (Online), São Paulo, v. 32, n. 2, p. 127-144, maio-ago. 2019

DURAS, M. Écrire. Paris: Gallimard, 1993.

FECHNER, T. G. Da anatomia comparada dos anjos. Sobre a dança. Trad. P. Neves. São Paulo: Editora 34, 1998.

INGOLD, T. Being Alive. Essays on movement, knowledge and description. Londres: Routledge, 2011.

JAKOBSON, R. Linguística e Comunicação. Trad. I. Blikstein e J. P. Paes. São Paulo: Cultrix, 1995.

KRISTEVA, J. Introdução à semiologia. Trad. L. H. França. São Paulo: Perspectiva, 1974.

. Seule une femme. Paris: Éditions de l'Aube, 2013.

. CLÉMENT, C. O feminino e o sagrado. Trad. R. Gutiérrez. Rio de Janeiro: Rocco, 2001.

LISLE, L. Portrait of an Artist: A Biography of Georgia O'Keeffe. Nova Iorque: Washington Square Press, 1981.

LOPES, A. Antologia. São Paulo: Cosac \& Naify, 2002.

. Manhã. Porto: Assírio \& Alvim, 2015.

. Bandolim. Porto: Assírio \& Alvim, 2016.

MALLARMÉ, S. Euvres complètes. Pléiade. Paris: Gallimard, 1947.

MARTELO, R. M. “As Armas Desarmantes de Adília Lopes”. In. Didaskalia XL, 2010, p. 207-222.

MICHAUX, H. Emergences-Résurgences. Genève: Éditions d'Art, 1993.

MUKAROVSKY, J. Escritos de Estética y Semiótica del Arte. Trad. A. Anthony-Visová. Barcelona: Editorial Gustavo Gili, 1975.

PAES, J. P. “Erotismo e poesia. Dos gregos aos surrealistas”. In. Poesia erótica em tradução. São Paulo: Companhia das Letras, 1990, p. 13-23.

PEDROSA, C. “Adília e Baudelaire: leituras do fim”. In. Ensaios sobre poesia e contemporaneidade. Niterói: EDUFF, 2011, p. 197-209.

PIGNATARI, D. Comunicação poética. São Paulo: Cortez \& Moraes, 1978.

SARTRE, J-P. Esboço para uma teoria das emoções. Trad. P. Neves. Porto Alegre: L\&PM, 2008.

SEGAL, H. Introdução à obra de Melanie Klein. Trad. J. C. Guimarães. Rio de Janeiro: Imago, 1975. 
Linha D'Água (Online), São Paulo, v. 32, n. 2, p. 127-144, maio-ago. 2019

SILVESTRE, O. M. “As lenga-lengas da menina Adília”. In. Florbela Espanca Espanca (posfácio). Lisboa: Black Sun Editores, 1999, p. 37-77.

SONTAG, S. A vontade radical. Trad. J. R. Martins Filho. São Paulo: Companhia das Letras, 1987.

VALÉRY, P. Degas Dança Desenho. Trad. C. Euvaldo. São Paulo: Cosac \& Naify, 2003.

VINCENT, G. "Uma história do segredo". In. História da vida privada 5. Da primeira guerra a nossos dias. Trad. D. Bottmann. São Paulo: Companhia das Letras, 2009, p. 137-364.

WILSON, F. Literary Seductions. Compulsive Writers and Diverted Readers. Nova York: St. Martin's Press, 2000.

Jogos Florais. "Adília Lopes. Entrevista". In. Folha de Poesia http://folhadepoesia.blogspot.com.br/2017/09/adilia-lopes.html. Último acesso em 30 de janeiro de 2018.

Recebido em 10/03/2019.

Aprovado em 13/06/2019.

Recebido em data.

Aprovado em data. 